\title{
Health Profile of Faculty and Staff at the Adventist University of the Philippines: A Basis for Workplace Health Promotion
}

\author{
Dr. Henry Eementary Kpoeh, Jr.* and Dr. Clint C. Laborde \\ Adventist University of the Philippines \\ *Corresponding Author: eekpoeh@yahoo.com
}

\begin{abstract}
This study determined the health profile of faculty and staff at the Adventist University of the Philippines. Using the descriptive research design, a total of 83 respondents participated in the study. Results of the descriptive analysis revealed an overall good health status of the respondents. There were however, few occurrences of poor health profile in terms of high systolic blood pressure (41\%), high diastolic blood pressure (31.3\%), low back pain (18.1\%), asthma (10.8\%) and sinusitis (7.2\%). Additionally, 38.2\% of respondents experienced anxiety and $19.7 \%$ experienced sleep disturbance. There was a difference in gender based on waist-to-hip ratio (WHR) finding. Based on the WHR results, more than half (56\%) of the female respondents were at high risk (WHR $\geq 0.86$ ) for cardiovascular diseases, while only $3 \%$ of the male counterparts had a moderate risk (WHR 0.96-1.0) for cardiovascular and other non-communicable diseases. In fact, none (0\%) of the male respondents was at high risk for cardiovascular diseases. Amidst the few occurrences of poor health, the respondents experienced considerable life enjoyment and exhibited high priority for attaining their health goals. Respondents are therefore entreated to engage in healthy lifestyle practices (exercise, healthy eating and stress management), avail for regular check-ups and screenings and access medical services in order to prevent and/or control chronic lifestyle-related diseases.
\end{abstract}

Keywords: Physical life, emotional state, stress, life enjoyment, quality of life, health profile

\section{Introduction}

The escalating rates of chronic lifestyle diseases among workers, coupled with the impact on work quality and productivity call for employers to establish workplace health promotion programs. Health promotion requires the collaboration of employers, employees and society to foster the health of employees in the workplace. The idea involves improving the work organization and working environment, increasing workers' participation in shaping the working environment and encouraging personal skills and professional development (WHO, 2017).

Workplace is an integral part of human environment. Because no occupation is hazard-free, workplace should provide an essential avenue for health protection, health promotion and disease prevention programs. The health and efficiency of workers in any organization is greatly influenced to a large extent by conditions in the working environment. Thus, workplace health programs can influence social norms, establish health-promoting policies, increase healthy behaviors such as dietary habits, physical activity and stress management, improve the health knowledge and skills of employees, increase employees' access to needed health services and decrease employees' on-the-job exposure to hazardous substances (Centers for Disease Control and Prevention, 2016).

It has been established that having a healthier workforce reduces direct costs in terms of insurance premiums and worker's compensation and may lower indirect costs associated with absenteeism and worker productivity (Sorensen, Barbeau, Stoddard, Hunt, Kaphingst \& Wallace, 2005). To this end, the US Bureau of Labor Statistics (2016) recommends that employers ensure a conducive workplace that fosters health of their workers.

The American Time Use Survey (2011) views the college environment as an ideal setting to promote 
health and wellbeing. In a study by Linnan et al. (2010), they surveyed 59 community college campuses. Of the 48 that responded, 13 (27\%) reported having some sort of structured wellness programs for their employees. Supportive environment, onsite physical activity resources, healthy food options and a committee or dedicated staff were shown to be essential elements of a successful workplace promotion program.

Hill-Mey, Kumpfer, Merrill, Reel, Hyatt-Neville and Richardson (2015) found college setting to be conducive for implementing health promotion programs, even though the large and diverse employee population may pose some challenges. Furthermore, the authors argued that there were not sufficient studies to indicate the strengths and weaknesses of health promotion programs in the college setting.

Studies have indicated the existing impact of bad health on labor force. The study of van, Robroek, Brouwer and Burdorf (2014), for instance, established that self-rated poor health is a risk factor for disability benefit [relative risk (RR) 3.61], unemployment (RR 1.44) and early retirement (RR 1.27). A study by Reeuwijk, van Klaveren, van Rijn, Burdorf and Robroek (2017) found European workers with poor health to be more prone to exiting the labor force than workers with good health. Notably, older workers with a poor selfrated health were at risk of leaving paid employment.

Over-loaded and under staffed workers including healthcare providers are susceptible to poor mental and physical health. The study by Mishra, Mehta, Sinha, Ahmed and Kawatra (2011) reported that poor work culture was the key stressor which led to job dissatisfaction. Poor departmental organization, lack of cohesiveness in departments, difficult superiors and juniors were found to be key work environmental stressors. Harassment, favoritism, discrimination and denial of self-expression $(P \leq$ 0.003 ) led to dissatisfaction on the job.

In the US, chronic lifestyle diseases including heart disease, depression and musculoskeletal disorders are the leading physical and mental health conditions causing huge medical costs and reduced productivity to employers. In response to this crisis, effective workplace health programs and policies have been recommended to decrease health risks and improve the quality of life for 138 million workers in the United States (Centers for Disease
Control and Prevention, 2016). To determine the prevalence and incidence of low back pain (LBP), Goetzel, Thomas, D'Arco \& Yarborough (2015) used claims and demographic data of 1 million workers from a group of 18 US benchmark companies and compared with the Lockheed Martin Corporation. The prevalence of LBP in the Market Scan normative group was $15.6 \%$ in the final study year (2012), while the incidence of new cases was $7.2 \%$ in 2011 and $7.3 \%$ in 2012. Compared with the normative group, the company's prevalence and incidence rates were lower. Furthermore, women and older workers were more likely to experience LBP compared with men and younger workers.

Another health condition that is a determinant of disease and fatality among workers is obesity. A research by Damorou et al. (2013) determined the prevalence of obesity and its risk factors among Togolese workers. Results revealed that $30.6 \%$ of the study's population were obese [Body Mass Index $(\mathrm{BMI})>30 \mathrm{~kg} / \mathrm{m}^{2}$ ] with $39.4 \%$ having abdominal obesity. Being a female $(p<0.0001)$, low education level $(\mathrm{OR}=2.4595 \% \mathrm{Cl}: 1.78-4.55, \mathrm{p}=0.001)$ and physical inactivity or sedentary lifestyle (OR $=3.57$ 95\% Cl $=2.34-9.67, \mathrm{p}=<0.001$ ) were significantly related to obesity. The body mass index had a positive correlation with age $(r=0.145, p=0.0004)$, and diastolic blood pressure $(r=0.10, p=0.013)$ and waist circumference also had a positive correlation with age $(r=0.381, p<0.0001)$.

In the Philippines, studies have focused on the health status of college students and not faculty and administrators. However, one study, Tan (2017) identified predictors of stress among Filipino professors in public universities. Findings of the study revealed that age, job satisfaction, work load and negative religious coping predicted stress among the respondents. Additionally, there were significant negative associations between job satisfaction and factors causing stress, relative to reward and recognition and impact of department or college.

Therefore, the alarming rates of chronic lifestyle diseases among workers, coupled with the impact on work quality and productivity called for employers to establish workplace health promotion programs. With less attention given by researchers to investigate the health status of faculty members at the universities in the Philippines, the researchers sought to determine the health status of employees of the Adventist University of the Philippines (AUP). 
Findings of the assessment would inform the development of workplace health promotion programs for AUP employees.

\section{Research Methodology}

This section presents the study design, population and sampling technique, instrumentation, data gathering procedures, ethical considerations and statistical treatment of data.

\section{Research Design}

The study utilized a descriptive research design. This approach allowed the researchers to describe the health profile of selected faculty and staff members of the Adventist University of the Philippines. According to Gravetter and Forsano (2003), descriptive survey describes a single variable but when multiple variables are involved, it gives separate description for each variable.

\section{Population and Sampling}

The study recruited faculty and staff of the Adventist University of the Philippines during the academic year 2016-2017. A total of 83 (15\% of the total Faculty and Staff population) was randomly selected to participate in the study.

\section{Instrumentation}

The instruments used in this study were survey questionnaire, weighing scale, tape measure and height device. Survey questionnaire consisted of six sections. The first section dealt with demographic profile of respondents; the second section involved the health assessment of the respondents, the third section comprised of the medical history of the respondents; the fourth section dealt with behavioral health problem checklist; the fifth section involved the health life and symptoms which comprised of physical, emotional, stress, life enjoyment and quality of life; and the sixth section dealt with health goals of the respondents.

\section{Ethical Considerations}

Ethical clearance was obtained from the Ethics and Review Board of AUP to conduct the research. The university provided permission for the researchers to publish results of this study. Informed consent (written) was secured from participants before partaking in the study. The study adhered to strict anonymity as well as confidentiality as respondents' identities were hidden.

\section{Statistical Treatment of Data}

The data were treated using the Statistical Package for Social Science (SPSS) software. Percentages were used to describe the demographics, medical history and behavioral health problems of respondents; systolic values and diastolic values were used to assess the level of blood pressure; waist-to-hip ratio values were used to determine respondents' susceptibility to cardiovascular diseases (CVD); and means were used to describe the physical life symptoms, mental/emotional state, stress level, quality of life, level of life enjoyment and health goals of the respondents.

\section{Results and Discussion}

This section presents the results of the study based on the analysis of data and review of related literature.

\section{Socio-demographic Profile of Respondents}

As shown in table 1 , this section gives the demographic profile of respondents in terms of age, sex, department/college, work status, position, length of service and residence. Of the 83 faculty and staff who enrolled in the study, the age range $36-45$ accounted for about one-third $(29,34.9 \%)$, followed by the age range of $46-55$ (24.1\%), the age range of $26-35(19.3 \%)$ and the age range of 56 years and above $(16,19.3 \%)$. There were two missing data, representing $2.4 \%$ because two of the participants did not indicate their age range. In terms of sex distribution, more than half 50 (60.2\%) were females while 33 (39.8\%) were males.

When the respondents were categorized in terms of department/college, majority 23 (27.7\%) came from the College of Allied Health, followed by 14 (16.9\%) and $10(12 \%)$ that came from the College of Nursing and College of Business, respectively. The College of Dentistry (1.2\%) and cafeteria section (2.4\%) accounted for the least of the respondents surveyed.

As shown in table 1, majority 70 (84.3\%) of the respondents were regular employees, followed by 11 (13.3\%) who were full-time contractual employees and 2 (2.4\%) who were part-time contractual employees. Relative to position, more than half 54 (65.1\%) of the respondents were faculty members, followed by 13 (15.7\%) who were nonteaching staff. Administrators constituted the least $(1.2 \%)$ of the respondents surveyed.

Table 1 also shows the length of service of respondents prior to the assessment. Thirty-seven (44.6\%) had served for 10 years and below, 30 (36.1\%) had served from $11-20$ years and 10 (12\%) 
had served for 21-30 years. Respondents serving 31 years and above accounted for the least (7.2\%). In terms of residential status, majority $(46,55.4 \%)$ of the respondents lived off-campus while 37 (44.6\%) lived in-campus (within the University premises).

Table 1: Socio-demographic Profile of Respondents

\begin{tabular}{|c|c|c|}
\hline Category & Number & Percent \\
\hline \multicolumn{3}{|l|}{ AGE OF RESPONDENTS } \\
\hline $26-35$ & 16 & 19.3 \\
\hline $36-46$ & 29 & 34.9 \\
\hline $46-55$ & 20 & 24.1 \\
\hline 56 AND ABOVE & 16 & 19.3 \\
\hline Missing & 2 & 2.4 \\
\hline TOTAL & 83 & 100 \\
\hline \multicolumn{3}{|l|}{ SEX } \\
\hline Male & 33 & 39.8 \\
\hline Female & 50 & 60.2 \\
\hline TOTAL & 83 & 100 \\
\hline \multicolumn{3}{|l|}{ DEPARTMENT/ COLLEGE } \\
\hline College of Nursing & 14 & 16.9 \\
\hline College of Health & 8 & 9.6 \\
\hline College of Theology & 4 & 4.8 \\
\hline College of Business & 10 & 12.0 \\
\hline College of Arts and Humanities & 23 & 27.7 \\
\hline College of Dentistry & 1 & 1.2 \\
\hline College of Education & 6 & 7.2 \\
\hline College of Science and Tech & 5 & 6.0 \\
\hline Administration & 3 & 3.6 \\
\hline Cafeteria & 2 & 2.4 \\
\hline Housing & 3 & 3.6 \\
\hline Community Extension Services & 4 & 4.8 \\
\hline TOTAL & 83 & 100 \\
\hline \multicolumn{3}{|l|}{ WORK STATUS } \\
\hline Regular & 70 & 84.3 \\
\hline Full Time Contractual & 11 & 13.3 \\
\hline Part Time Contractual & 2 & 2.4 \\
\hline TOTAL & 83 & 100 \\
\hline \multicolumn{3}{|l|}{ POSITION } \\
\hline Administration & 1 & 1.2 \\
\hline Director & 2 & 2.4 \\
\hline Dean & 3 & 3.6 \\
\hline Department Chair & 4 & 4.8 \\
\hline Teaching Faculty & 54 & 6.5 \\
\hline Clinical Instructor & 6 & 7.2 \\
\hline Non-Teaching Staff & 13 & 15.7 \\
\hline TOTAL & 83 & 100 \\
\hline \multicolumn{3}{|l|}{ LENGTH OF SERVICE } \\
\hline 10 years and below & 37 & 44.6 \\
\hline $11-20$ & 30 & 36.1 \\
\hline $21-30$ & 10 & 12.0 \\
\hline 31 years and above & 6 & 7.2 \\
\hline TOTAL & 83 & 100 \\
\hline \multicolumn{3}{|l|}{ RESIDENCE } \\
\hline In campus & 37 & 44.6 \\
\hline Off campus & 46 & 55.4 \\
\hline TOTAL & 83 & 100 \\
\hline
\end{tabular}




\section{Health Profile Status of Respondents}

This section describes the health profile status of the study participants in terms of blood pressure, waist-hip-ratio, medical history, behavioral health problems, physical life/health symptoms, mental/emotional health, stress evaluation, life enjoyment, quality of life and health goals.

\section{Level of Blood Pressure}

Table 2 shows the level of blood pressure of respondents where more than half 49 (59\%) had a normal systolic blood pressure of $120 \mathrm{mmHg}$ and below, while $34(41 \%)$ recorded a high systolic blood pressure of above $120 \mathrm{mmHg}$. Fifty-seven $(68.7 \%)$ of the respondents recorded a normal diastolic blood pressure of $80 \mathrm{mmHg}$ and below, while 26 (31.3\%) had a high diastolic pressure of above $80 \mathrm{mmHg}$. Even though majority of the respondents had a normal blood pressure, it is very important to monitor and control the blood pressure in order to maintain adequate health status.

Table 2: Level of Blood Pressure of Respondents

\begin{tabular}{lccc}
\hline \multicolumn{1}{c}{ Category } & N & Percent & Verbal Interpretation \\
\hline SISTOLIC BLOOD PRESSURE & & & Normal \\
$120 \mathrm{mmHg}$ and below & 49 & 59.0 & High \\
Above $80 \mathrm{mmHg}$ & 34 & 41.0 & Normal \\
TOTAL & $\mathbf{8 3}$ & $\mathbf{1 0 0}$ & High \\
DIASTOLIC BLOOD PRESSURE & & 68.7 & 31.3 \\
120 mmHg and below & 57 & $\mathbf{1 0 0}$ & \\
Above $80 \mathrm{mmHg}$ & 26 & & \\
TOTAL & $\mathbf{8 3}$ & & \\
\hline
\end{tabular}

Table 3: Extent of waist-to-hip ratio

\begin{tabular}{lccllccc}
\hline \multicolumn{1}{c}{ WHR value } & $\mathbf{N}$ (Male) & $\mathbf{\%}$ & Health Risk & \multicolumn{1}{c}{ WHR Value } & $\mathbf{N}$ (Female) & \% & Health Risk \\
\hline 0.95 or Below & 32 & 97 & Low Risk & 0.80 or Below & 7 & 14 & Low Risk \\
$0.96-1.0$ & 1 & 3 & Moderate Risk & $0.81-0.85$ & 15 & 30 & Moderate Risk \\
1.1 and Above & 0 & 0 & High Risk & 0.86 and Above & 28 & 56 & High Risk \\
TOTAL & $\mathbf{3 3}$ & $\mathbf{1 0 0}$ & & TOTAL & $\mathbf{5 0}$ & $\mathbf{1 0 0}$ & \\
\hline
\end{tabular}

The results differ from that of a study by Fikadu and Lemma (2016) in Ethiopia that showed high burden of hypertension among teachers and bankers. Bulk (70.3\%) of the participants in this study were teachers. Among the factors presented, the socioeconomic factors were strongly associated with the odds of having hypertension (Adjusted Odd Ratio 2.17 with 95\% Cumulative Incidence 1.582.98). This study resulted to the promotion of healthy behaviors and interventions that targeted higher income groups. Furthermore, in a study about the health profile of Australian employees, Magee (2014) found about 1 in 10 (10.0\%) workers to have high blood pressure and nearly a quarter $(23.8 \%)$ to have high cholesterol. Elsewhere, a Nigerian study recorded a relatively high prevalence (34.9\%) of blood pressure among employees of Obafemi Awolowo University. The distribution of teaching to non-teaching was $20.1 \%$ and $14.8 \%$ respectively (Adedoyin et al., 2016).

\section{Extent of Waist-to-Hip Ratio (WHR)}

The Waist-to-Hip Ratio (WHR) was one tool used to measure the respondent's risk for cardiovascular disease and other non-communicable diseases.
Table 3 shows the extent of WHR of respondents where majority $(32,97 \%)$ of the males were at low risk (WHR $\leq 0.95)$ for cardiovascular disease (CVD), followed by 1 (3\%) that was moderate risk (WHR 0.96-1.0) for CVD. None (0\%) of the males was high risk for CVD.

In the female category, more than half (56\%) were at high risk (WHR $\geq 0.86)$ for cardiovascular disease, while 15 (30\%) with WHR of 0.81 to 0.85 and 7 (14\%) with WHR $\leq 0.80$ were at moderate risk and low risk for cardiovascular disease, respectively.

The current study's findings suggest that respondents, particularly females, should endeavor to attain and maintain normal body weight to prevent or reduce the risk of cardiovascular diseases. These results are consistent with Dankyau et al. (2016) who found $23.2 \%$ of workers obese, $31.4 \%$ overweight and $60 \%$ abdominally obese. Female workers had higher waist-to-hip ratio and higher mean waist circumference compared to their male counterpart $(92.1 \pm 11.8 \mathrm{~cm}$ vs. $83.0 \pm 9.8$ $\mathrm{cm}, P=0.016$, Odd Ratio 9.1, 95\% Cl 6.0-12.3). A Togolese study also found female worker to be 
more obese than male worker. Waist circumference, one of the indicators for measuring waist-to-hip ratio was positively correlated to age $(r=0.381$, $\mathrm{p}<0.0001$ ) (Damorou et al., 2013). Additionally, a study by Adedoyin et al. (2016) recorded high body mass index and waist circumference in both the teaching and non-teaching staff in a Nigerian university.

\section{Medical History}

Table 4 presents the most critical medical history of respondents where $24(28.9 \%)$ had high blood pressure, 15 (18.1\%) had low back pain and 9 $(10.8 \%)$ had asthma. Respondents with sinusitis and tonsillitis accounted for $7.2 \%$ of the employees surveyed. Diabetes mellitis accounted for the least
(1.2\%) prevailing medical conditions amongst respondents.

Compared to our results, a study by Darwish and AlZuhair (2013) reported a higher prevalence of musculoskeletal pain disorders (79.17\%) among secondary school teachers in Saudi Arabia (KSA). Major sites of pain were lower back $(63.8 \%)$ followed by shoulder $(45.4 \%)$, neck $(42.1 \%)$, leg (40.0\%), wrist (16.2\%) and elbow joint (10.0\%). Type of school (value 0.038), age (value 0.002), weight (value 0.007), number of children (value 0.006), shoe type (value 0.000), teaching years (value 0.003) and working daily hours (value 0.027) were factors responsible for musculoskeletal pain disorders among Saudi teachers.

Table 4: Medical History of Respondents

\begin{tabular}{lcc}
\hline Medical Condition & N & Percent \\
\hline Blood Pressure & 24 & 28.9 \\
Low Back Pain & 15 & 18.1 \\
Asthma & 9 & 10.8 \\
Sinusitis & 6 & 7.2 \\
Tonsillitis & 6 & 7.2 \\
Gouty Arthritis & 4 & 4.8 \\
Kidney Stone & 3 & 3.6 \\
Urinary Tract Infection & 3 & 3.6 \\
Hearing Loss & 3 & 3.6 \\
Heart Disease & 3 & 3.6 \\
Pneumonia & 2 & 2.4 \\
Myopia & 2 & 2.4 \\
Tuberculosis & 2 & 2.4 \\
Diabetes Mellitus & 1 & 1.2 \\
& 83 & 100 \\
\hline
\end{tabular}

Table 5: Behavioral health problem of respondents

\begin{tabular}{lcc}
\hline \multicolumn{1}{c}{ Medical Condition } & N & Percent \\
\hline Anxiety & 29 & 38.2 \\
Sleep Disturbance & 15 & 19.7 \\
Loss of Family Members & 11 & 14.5 \\
Mood Swing & 7 & 9.2 \\
Anger Aggression & 6 & 7.9 \\
Eating Disorder & 3 & 3.9 \\
Psychological Stress & 3 & 3.9 \\
Addiction to Social Media & 2 & 2.6 \\
TOTAL & $\mathbf{7 6}$ & $\mathbf{1 0 0}$ \\
\hline
\end{tabular}

\section{Behavioral Health Problems}

One of the indicators used to assess the health profile of respondents was the behavioral health problems. Twenty-nine (38.2\%) of the respondents had experienced anxiety, followed by 15 (19.7\%) who had experienced sleep disturbance and 11 (14.5\%) who had experienced loss of family member. Respondents who were addicted to social media accounted for the least (2.6\%).
The findings agree with a study by Mustafa and Saadi (2018) who determined the level of anxiety and motivation among kindergarten and grade one teachers in Saudi Arabia. The level of anxiety was higher in female teachers, while the level of motivation was higher in male Gender and workplace affected the levels of teachers' motivation and anxiety. Ashrafi-rizi et al. (2014) 
conducted a study on anxiety level among the faculty members of Isfahan University of Medical Sciences (IUMS). Accordingly, the average researchrelated anxiety among IUMS faculty was about 3.27 \pm 0.536 . The highest scores in descending order were associated with lack of timely payment of fees (3.97 \pm 0.961$)$, the long approval process of proposals and research project reporting (3.86.土0.99) and lack of research efficiency on the part of faculty (3.70 \pm 1.00$)$. The lowest scores were related to having insufficient funds to conduct research (2.67 \pm 1.08$)$, another's understanding of inability for researching $(2.84 \pm 1.192)$ and unfriendly behavior from journals and research center staff (2.89 \pm 0.802$)$. On the other hand, Swanson et al. (2010) noted chronic sleep deprivation among
American workers. One-thousand Americans who work 30 hours per week or more were asked questions about employment, work performance and sleep. Results show that long work hours were associated with shorter sleep times, and shorter sleep times were associated with more work impairments. Thirty-seven percent of respondents were classified as at-risk for any sleep disorder.

\section{Physical Life/Health Symptoms}

Table 6 shows the physical life/health symptoms of the respondents. The overall mean for the physical life/health symptoms of the respondents was 1.9036, indicating that the respondents rarely experienced physical/health symptoms. However, regarding physical life, respondents often worked out or engaged in activity (mean $=3.8675$ ).

Table 6: Physical life/health symptoms of the respondents

\begin{tabular}{llc}
\hline SYMPTOM & MEAN & VERB INTERPRETATION \\
\hline Ability to work out or engage in activity & 3.8675 & Often \\
Feeling tension, stiffness, lack of flexibility & 2.2530 & Rarely \\
Incidence of allergies, eczema or skin rash & 1.9759 & Rarely \\
Incidence of cold or flu & 2.2651 & Rarely \\
Incidence of dizziness, nausea & 1.8916 & Rarely \\
Incidence of fatigue or low energy & 2.1084 & Rarely \\
Incidence of diarrhea or constipation & 1.9518 & Rarely \\
Presence of body pain like neck/back pain etc & 2.3373 & Rarely \\
Chest pain, palpitations & 1.8072 & Never \\
Coughing out blood & 1.1566 & Never \\
Swollen joints & 1.2169 & Rarely \\
Overall mean & 1.9036 & \\
\hline
\end{tabular}

Legend: 1.0-1.49 =Never, 1.50-2.49 =Rarely, 2.50-3.49 =Sometimes, 3.50-4.49=Often, 4.50-5.00=Always

Table 7: Mental/emotional state of the respondents

\begin{tabular}{llc}
\hline \multicolumn{1}{c}{ Mental/Emotional State } & Mean & Verbal Interpretation \\
\hline Being overly worried about small things & 1.9759 & Rarely \\
Difficulty falling or staying asleep & 2.1205 & Rarely \\
Difficulty thinking or concentrating & 1.9277 & Rarely \\
Feeling of depression or anxiety & 1.7470 & Rarely \\
Moodiness, temper, or angry outbursts & 1.9518 & Rarely \\
Presence of negative feelings or negative energy & 1.9639 & Rarely \\
Overall Mean & 1.9478 & Rarely \\
\hline
\end{tabular}

Legend: 1.0-1.49 =Never, 1.50-2.49 =Rarely, 2.50-3.49 =Sometimes, 3.50-4.49 =Often, 4.50-5.00=Always

Darwish and Al-Zuhair (2013) do not support the findings of this study. They conducted a crosssectional study to estimate the prevalence of musculoskeletal pain disorders among secondary school teachers (public and private schools) in Saudi Arabia (KSA). Results revealed the high (79.1\%) prevalence of musculoskeletal pain disorders among the study participants. Main sites of pain were lower back $(63.8 \%)$ followed by shoulder (45.4\%), neck (42.1\%), leg (40.0\%), wrist (16.2\%), and elbow joint (10.0\%). Factors that showed significant relationship were type of school (value 0.038), age (value 0.002), weight (value 0.007), number of children (value 0.006), shoe type (value 0.000), teaching years (value 0.003), and working daily hours (value 0.027).

\section{Mental/Emotional State}

As part of the process of describing the health profile of respondents, the mental/emotional state was considered. Table 7 shows the mental/emotional state of the respondents, with an 
overall mean of 1.9478 . This indicates that the respondents rarely experienced mental/emotional feelings. Respondents rarely faced difficulty in falling or staying asleep with a mean of 2.1205.

Even though the results reveal that respondents rarely experienced mental/emotional feelings, they suggest that respondents should continue to handle the condition of relative insomnia (difficulty in falling asleep) due to stress. These findings somewhat agree with a study by Sabherwal et al. (2015) that investigated occupational stress among faculty members in higher educational institutions in Pune, India. The researchers found that factors causing maximum stress were lack of regular breaks (85\%) and long working hours (83\%). Seventy three percent $(73 \%)$ of the respondents felt lack of communication with staff; only $18 \%$ of the respondents felt neutrally stressed out due to work not valued, whereas $37 \%$ of respondents felt occasionally stressed out due to new styles of institutional management. Furthermore, Keller and colleagues found emotional exhaustion (EE), a core component of teacher burnout, to negatively impact teachers' professional lives. Accordingly, in 39\% of all lessons, teachers experienced anger, whereas they experienced anxiety less frequently. Teachers reported suppressing or faking their emotions during roughly a third of all lessons (Keller et al., 2014). Ferguson and colleagues investigated the predictors of anxiety, depression, and job satisfaction in teachers in northern Ontario. Using data from self-report questionnaires, the study found workload and student behavior and employment conditions as determinants of depression and anxiety in teachers (Ferguson et al., 2012). Elsewhere, a study by Panari and Simbula (2016) noted the mediating role played by presenteeism on the relationships with work tasks, work-to-family conflict and emotional exhaustion among Italian schoolteachers. Utilizing a self-report questionnaire, the study surveyed 264 secondary school teachers.

\section{Stress Evaluation}

Table 8 shows the stress evaluation of the respondents, where the overall mean is 2.6695 . This indicates that the respondents sometimes experienced stress conditions. Among the factors responsible for the stress experienced by respondents, work (mean $=2.9277$ ) and finances (mean $=2.9157$ ) accounted for the highest.

Table 8: Stress evaluation of the respondents

\begin{tabular}{lcc}
\hline \multicolumn{1}{c}{ Mental/ Emotional State } & Mean & Verbal Interpretation \\
\hline Coping with daily problems & 2.6627 & Sometimes \\
Personal issues & 2.5783 & Sometimes \\
Family & 2.4819 & Rarely \\
Finances & 2.9157 & Sometimes \\
Health & 2.6506 & Sometimes \\
Relationships & 2.4699 & Rarely \\
Work & 2.9277 & Sometimes \\
Overall mean & 2.6695 & Sometimes \\
\hline
\end{tabular}

Legend: 1.0-1.49 =Never, 1.50-2.49 =Rarely, 2.50-3.49 =Sometimes, 3.50-4.49 =Often, 4.50-5.00=Always

These results parallel a study by Sabherwal et al. (2015) that determined occupational stress level among faculty members in higher educational institutions in Pune, India. The researchers found the lack of regular breaks (85\%) and long working hours $(83 \%)$ to cause maximum stress among faculty. Seventy three percent (73\%) of the respondents felt lack of communication with staff, $18 \%$ felt stressed out due to underrated work performed and $37 \%$ felt occasionally stressed out due to new styles of institutional management. An English study by Kinman and Wray (2013) reported that nearly three-quarters of the study population strongly agreed that faculty and staff jobs and responsibilities are stressful. More than half indicated that their general level of stress was high or very high, and more than one third always experienced levels of stress they found unacceptable. Colnerud (2015) said moral stress in teaching practice usually occurs when teachers act contrary to their consciences. Accordingly, institutional constraints compel teachers to act in ways that contravene their own morals.

\section{Life Enjoyment}

Table 9 shows the level of life enjoyment of the respondents, with an overall mean of 4.1205 . This indicates that the respondents experienced considerable life enjoyment. Having interest in 
maintaining a healthy lifestyle (mean = 4.2651), having compassion and accepting others (mean = 4.2048) and the ability to handle adversity (mean =
4.1566) were major contributors to the respondents experiencing considerable life enjoyment.

Table 9: Level of life enjoyment of respondents

\begin{tabular}{lcc}
\hline \multicolumn{1}{c}{ Life Enjoyment } & Mean & Verbal Interpretation \\
\hline Confidence in ability to handle adversity & 4.1566 & Considerable \\
Compassion and acceptance of others & 4.2048 & Considerable \\
Experiences of relaxation, ease or wellbeing & 4.0602 & Considerable \\
Interest in maintaining a healthy lifestyle & 4.2651 & Considerable \\
Time devoted to things you enjoy & 4.0964 & Considerable \\
Level of recreation in your life & 3.9398 & Considerable \\
Overall Mean & 4.1205 & Considerable \\
\hline
\end{tabular}

Legend: 1.0-1.49 =None, 1.50-2.49 =Slight, 2.50-3.49 =Moderate, 3.50-4.49 =Considerable, 4.50-5.00=Extensive

Table 10: Quality of life of Respondents

\begin{tabular}{lll}
\hline Quality of Life & Mean & Verbal Interpretation \\
\hline Handling problems in your life & 4.0361 & Satisfied \\
Adjusting to changes in your life & 4.0000 & Satisfied \\
The work you do & 4.0964 & Satisfied \\
Your personal life & 4.0602 & Satisfied \\
Your physical appearance & 4.0723 & Satisfied \\
Suitable spouse & 4.1807 & Satisfied \\
Making decisions & 4.0482 & Satisfied \\
Dealing with conflict & 4.0120 & Satisfied \\
Asserting yourself & 3.9639 & Satisfied \\
Getting along with people & 4.1446 & Satisfied \\
Living situation/condition & 4.0120 & Satisfied \\
Overall mean & 4.0570 & Satisfied \\
\hline
\end{tabular}

Legend: 1.0-1.49 =Very dissatisfied, 1.50-2.49 =dissatisfied, 2.50-3.49 =moderately satisfied, 3.50-4.49=Satisfied, 4.50$5.00=$ Very satisfied

The findings are supported by Wesarat et al. (2015) that found culture to moderate the relationship between employment status, income, friendship, work responsibilities and happiness at the workplace. The researchers found happiness to be crucial to improving productivity in any organization. A study by Mukhtar (2012) utilized the existing database from the lowa State University 2009-2010 to explore faculty work life balance and job satisfaction among academic disciplines. Results revealed considerable job enjoyment among faculty and was tied to good work life. Age and climate, culture and collegiality were determinants of job satisfaction or enjoyment. Also, the level of job enjoyment (satisfaction) was lower for hard pure disciplines as compared to soft pure disciplines in lowa State University.

\section{Quality of Life}

Table 10 shows the quality of life of the respondents, where the overall mean is 4.0570 shows that the respondents were satisfied with their overall quality of life. Getting along with others $($ mean $=4.1446)$, having suitable spouse $($ mean $=$
4.1807), having a suitable job (mean $=4.0964)$ and being satisfied with one's physical appearance (mean $=4.0723)$ contributed to the satisfactory quality of life of the respondents.

The study's findings agree with Srivastava and Kanpur (2014) who described quality of life of faculty and staff wellbeing in Axis College, India. The researchers found high degree of quality of life to lead to job satisfaction and ultimately effective and efficient performance. Another study, Wesarat et al. (2015), found employees' happiness to differ in different cultural contexts. The authors concluded that happy people are productive people while those people who are unhappy may not pay full attention to any task. Narehan et al. (2014) examined the relationship between quality of work life programs and quality of life among Malaysian employees. The findings reveal work environment and job facets as key factors influencing the quality of life of the study participants. Researchers concluded that quality of work life (QWL) programs may influence quality of life (QOL) of employees in organization. 


\section{Health Goals}

Table 11 shows the health goals of the respondents, where the overall mean is 4.3157 . This shows that the respondents had high priority in terms of attaining their health goals. Spending quality time with family (mean $=4.5301$ ), taking time daily for spiritual revival $($ mean $=4.5060)$ maintaining a cheerful, hopeful outlook on life (mean $=4.4337)$ and eating more plant-based foods (mean $=4.3012$ ) contributed to respondents having high priority for attaining their health goals.

Table 11: Health goals of respondents

\begin{tabular}{lcc}
\hline \multicolumn{1}{c}{ Quality of Life } & Mean & Verbal Interpretation \\
\hline Get adequate rest daily & 4.2048 & High \\
Get regular physical activity & 4.1566 & High \\
Eat more plant-based foods & 4.3012 & High \\
Eat more whole-grain breads \& cereals & 4.2771 & High \\
Achieve/maintain a healthy weight & 4.0723 & High \\
Choose healthy fats & 4.1205 & High \\
Be free of dependence on tobacco, illicit drugs or alcohol & 4.0482 & High \\
Maintain a cheerful, hopeful outlook on life & 4.4337 & High \\
Spend quality time with family & 4.5301 & High \\
Take time daily for spiritual revival & 4.5060 & High \\
Overall mean & 4.3157 & \\
\hline
\end{tabular}

Legend: 1.0-1.49 =Least priority, 1.50-2.49 =Less priority, 2.50-3.49=Moderate priority, 3.50-4.49=High priority, 4.50$5.00=$ Highest priority

Respondents of the current study have high priority for attaining their health goals; meaning, they are very concerned about their health and wellbeing. This is consistent with Miller and Suff (2016) who proffered that optimal health is the main priority of employees and employers. Employee's well-being should be the hallmark of every good leader in order to ensure conducive working environment. The researchers maintained that well employees are physically and mentally able, willing to contribute in the workplace and likely to be more engaged at work. In a previous study, Dieleman and Harnmeijer (2006) enumerated factors such as living conditions, financial considerations, working conditions, management capacity and style and work safety to affect employees' quality of life. The study revealed that staff retention can be achieved if their health goals and priorities such as personal and lifestylerelated factors are taken into consideration.

\section{Conclusion and Recommendations}

The respondents in this study generally had a good health status. However, there were few occurrences of poor health status like high blood pressure, low back pain, asthma, sinusitis, tonsillitis, anxiety and sleep disturbances. Remarkably, there was a difference in gender based on the waist-to-hip ratio results as more than half (56\%) of the female respondents were high risk (WHR $\geq 0.86$ ) for cardiovascular diseases, while only $3 \%$ of the male counterparts had a moderate risk (WHR 0.96-1.0) for cardiovascular and other non-communicable diseases. It is therefore advisable for respondents to engage in healthy lifestyle practices (exercise, healthy eating and stress management), avail for regular check-ups and screenings and access medical services in order to prevent and/or control chronic lifestyle-related diseases. AUP can play a pivotal role in this endeavor by establishing workplace health programs that focus on weight management, healthy nutrition, exercise and stress management. This will promote quality, long lives for employees and ultimately better out-turn to the institution and stakeholders.

\section{Reference}

Adedoyin, R., Awotidebe, T., Borode, A., Ativie, R.N, Akindele, M., Adeyeye, V. \& Johnson, $\mathrm{O}$. (2016).Comparison of Blood Pressure Patterns of Teaching and Non-Teaching Staff of a Nigerian University. International Journal of Clinical Medicine. DOI: 10.4236.

American Time Use Survey. Bureau of Labor Statistics (2011). [Last accessed on 2015 Feb 15]. Available from: http://www.bls.gov/tus/charts/

Ashrafi-rizi, H., Zarmehr, F., Bahrami, S., GhazaviKhorasgani, Z., Kazempour, Z. \& Shahrzadi, L. (2014). Study on Research Anxiety among Faculty Members of Isfahan University of Medical Sciences. Mater Sociomed. DOI: 10.5455. 
Centers for Disease Control and Prevention (2016). Workplace Health Promotion. Division of Population Health, National Center for Chronic Disease Prevention and Health Promotion.

Colnerud, G. (2015). Moral stress in teaching practice. Teachers \& teaching 21 (3): 346360.

Damorou, F., Yayehd, K., N'cho Mottoh, M.P., Tcherou, T., Ehlan, E., N`da, N.W. and Randrianarisoa, F. (2013). Prevalence and Determinants of Obesity among Workers in Lomé (Togo). Research Journal of Cardiology, 6: 19-27. DOI: 10.3923/rjc.2013.19.27.

Dankyau, M., Ayodele, J.,Oyebanji, E. \& Mamven, O. (2016). Prevalence and correlates of obesity and overweight in healthcare workers at a tertiary hospital. Journal of Medicine in the Tropics. DOI: 10.4103

Darwish' M. \& Al-Zuhair' S. (2013). Musculoskeletal Pain Disorders among Secondary School Saudi Female Teachers. Pain Research and Treatment. DOI: 10.1155

Dieleman, M. \& Harnmeijer, J. (2006). Improving health worker performance: in search of promising practices. World Health Organization. Department of Human Resource on Health.

Ferguson, K. (2012). Predicting Teacher Anxiety, Depression, and Job Satisfaction. Journal of Teaching and Learning VOL. 8 NO. 1. University David Hall Nipissing University.

Fikadu, G. \& Lemma, S. (2016). Socioeconomic Status and Hypertension among Teachers and Bankers in Addis Ababa, Ethiopia. International Journal of Hypertension (11): 1-7. DOI:10.1155/2016/4143962.

Goetzel, R., Thomas, J., D'Arco, M. \& Yarborough, C.M. (2015). Measuring the Prevalence and Incidence of Low Back Pain Disorders among American Workers in the Aerospace and Defense Industry. Journal of occupational and environmental medicine / American College of Occupational and Environmental Medicine, 57(9):998-1003. DOI: 10.1097/JOM.0000000000000512.
Gravetter, F. \& Forzano, L.B. (2003). Research Methods for the Behavioral Sciences $\left(6^{\text {th }}\right.$ ed.) Belmont, CA. www.books.google.com

Hill-Mey, P., Kumpfer, K., Merrill, R., Reel, J., HyattNeville, B. \& Richardson, G. (2015). Worksite health promotion programs in college settings. J Educ Health Promot. ; 4: 12. doi: 10.4103/2277-9531.154019.

Keller, M., Chang, M., Becker, E., Goetz, T. \& Frenze, A. (2014). Teachers' emotional experiences and exhaustion as predictors of emotional labor in the classroom: an experience sampling study. Frontiers in Psychology. DOI: 10.3389 .

Kinman, G. \& Wray, S. (2013). A Survey of Stress and Well-being among Staff in Higher Education. University College Union.

Linnan, L., Brooks, A., Haws, S., Benedict, S., Birken, B., French, E., Gizlice, Z. \& Britt, A. (2010). Community colleges as settings for promoting employee health. Am J Health Stud., 25:86-91.

Magee, C. (2014). Health Profile of Australian Employees: A study by the University of Wollongong in partnership with Workplace Health Association Australia (WHAA). Retrieved from http://www.MAGEE_Christopher_PPT_wha a14.pdf

Miller, J. \& Suff, R. (2016). Growing the health and well-being agenda: From first steps to full potential. Retrieved from http://www. health-well-being-agenda_2016-first-stepsfull-potential_tcm18-10453.pdf.

Mishra, B., Mehta, S.C., Sinha, N.D., Shukla, S.K., Ahmed, N. \& Kawatra, A. (2011). Evaluation of Work Place Stress in Health University Workers: A Study from Rural India. Indian J Community Med., 36(1): 39-44. doi: 10.4103/0970-0218.80792.

Mukhtar, F. (2012). Work life balance and job satisfaction among faculty at lowa State University. Graduate Theses and Dissertations. Paper 12791.

Mustafa, K. \& Saadi, A.S. (2018). Social-Psychological Variables of Kindergarten \& Grade One Teachers' Classroom Such as Anxiety \& Motivation Toward English as a Medium of 
Instruction in Regard with their Gender and Workplaces. Jurnal IImiah Peuradeum 19 (1): 1-15. DOI: 10.22373/jid.v4191.

Narehan, H., Hairunnisa, M., Norfadzillah, R. \&

Freziamella. L. (2014). The Effect of Quality of Work Life (QWL) Programs on Quality of Life (QOL) among Employees at Multinational Companies in Malaysia. Social and Behavioral Sciences. ISSN 1911-2025. Canadian Center of Science and Education

Panari, C. \& Simbula, S. (2016). "Presenteeism on the desk: The relationships with work responsibilities, work-to-family conflict and emotional exhaustion among Italian schoolteachers." International Journal of Workplace Health Management 9 (1):84-95. https://doi.org/10.1108/IJWHM-11-20130047.

Reeuwijk, K., van Klaveren, D., van Rijn, R., Burdorf, A. \& Robroek, S. (2017). The influence of poor health on competing exit routes from paid employment among older workers in 11 European countries. Scand J Work Environ Health, 43(1):24-33. doi:10.5271/sjweh.3601.

Sabherwal, N., Ahuja, D., George, M., \& Handa, A. (2015). A study on occupational stress among faculty members in Higher Education Institutions in Pune. SIMS Journal of Management Research Volume no. 1

Sorensen, G., Barbeau, E., Stoddard, A., Hunt, M., Kaphingst, K., \& Wallace L. (2005). Promoting behavior change among workingclass, multi-ethnic workers: results of the
Healthy Directions - Small Business Study. Am J Pub Health, 95(8):1389-1395.

Srivastava, S., \& Kanpur, R. (2014). A Study On Quality Of Work Life: Key Elements \& It's Implications. Journal of Business and Management (IOSR-JBM) Volume 16, Issue 3. Ver. I. ISSN: 2278-487X, p-ISSN: 23197668

Swanson, L., Arnedt, T., Rosekind, M., Belenky, G., Balkin, T. \& Drake, C. (2010). Sleep Disorders and Work performance. J. Sleep Res. DOI: 10.1111.

Tan, J.S.T. (2017). Factors Affecting Stress among Faculty Members of Public Universities in the Philippines: A Multiple Regression Analysis. International Journal of Psychological Studies 9(3):64. DOI:10.5539/ijps.v9n3p64

U.S. Bureau of Labor Statistics (2016). www.bls.gov

Van, R., Robroek, S., Brouwer, S. \& Burdorf, A. (2014). Influence of poor health on exit from paid employment: a systematic review. Occup Environ Med, 71(4): 295-301, http://dx.doi.org/10.1136/oemed-2013101591.

Wesarat, P., Sharif, M., Halim, A. \& Majid, A. (2015). A Conceptual Framework of Happiness at the Workplace. Asian Social Science; 11(2); ISSN 1911-2017

World Health organization (2017). Workplace health promotion: Occupational health /Occupational health topics. 